\title{
Erratum to: Validation of a social cohesion theoretical framework: a multiple group SEM strategy
}

\section{Gianmaria Bottoni ${ }^{1}$}

\section{Erratum to: Qual Quant DOI 10.1007/s11135-017-0505-8}

The reference Jenson (1998) was published incorrectly. The correct reference is provided below.

Jenson, J.: Mapping Social Cohesion: The State of Canadian Research. Canadian Policy Research Network (CPRN) Study No. Fl03, Ottawa, Canada (1998)

The online version of the original article can be found under doi:10.1007/s11135-017-0505-8.

$\bowtie$ Gianmaria Bottoni

gianmaria.bottoni@uniroma1.it

1 “La Sapienza” Università di Roma, Rome, Italy 